\title{
PENGAJARAN “ENGLISH FOR GUIDING” BERBASIS PENDEKATAN SOSIOKULTURAL
}

\author{
I Nengah Astawa \\ Program Studi Pendidikan Bahasa Inggris FKIP Unmas Denpasar
}

\begin{abstract}
Teaching English for specific purposes (ESP), which is in contrast with English for Academic purposes (EAP), has gained specially great attention since 1960 's. One of the examples of ESP is English for guiding. The main purpose of implementing English for tourism in some schools or collages is to give the students ability to communicate mainly orally so as to be able to fulfil the student's need for his or her future career. In reality very often cultural misunderstandings which may produce fatal consequences emerge among those who are involved in tourism industry. Due to this circumstance, inserting sosiocultural aspects in the teacher's language teaching interaction is indeed beneficial. In this case, the role of the teacher to include some cultural aspects in language teaching, beside giving formal grammatical language forms, of course is highly worth considering. Teaching English for tourism industry is not regarded appropriate yet if sosio-cultural aspects are not adequately included. In other words, beside teaching the language forms, English teacher should incorporate sosio-cultural aspects into his/her interaction.
\end{abstract}

Keywords : English for guiding, sosiokultural, kesenjangan budaya, multikultural.

\section{PENDAHULUAN}

Kurikulum di Program Studi Pendidikan Bahasa Inggris FKIP Unmas Denpasar memberikan mata kuliah yang disebut dengan bahasa Inggris untuk para pemandu wisata (English for tour guide) sebagai mata kuliah pilihan dan juga bahasa Inggris untuk hotel dan restoran. Tujuan mata kuliah "English for Guiding" adalah memberikan kompetensi kepada mahasiswa agar setelah menamatkan studinya di Program Studi Pendidikan Bahasa Inggris FKIP Unmas Denpasar mampu menggunakan bahasa Inggris untuk keperluan kerja di dunia pariwisata khususnya dalam memandu wisatawan mancanegara mengingat peluang untuk bekerja di sektor pariwisata masih sangat menjanjikan.

Pengajaran bahasa Inggris untuk keperluan khusus (English for Specific Purposes) menjadi sangat penting dalam pengajaran bahasa Inggris sejak 
dicetuskan pada akhir tahun 1960-an (Tom Hutchingson and Alan Waters, 1987). Jenis pengajaran bahasa asing untuk tujuan khusus tersebut bisa dibagi dua, yaitu yang pertama diistilahkan dengan "English for Academic Purposes" (EAP), yaitu bahasa Inggris untuk keperluan akademis, dan yang kedua dengan istilah "English for Vocational Purposes (EVP)”, yaitu bahasa Inggris yang berkaitan langsung dengan karier atau keperluan pekerjaan (job) (English Teaching Forum XXII, 1974:24). Sejumlah penyusun silabus bahasa Inggris untuk tujuan khusus telah bermunculan seiring dengan semakin larisnya buku-buku seperti itu di pasaran.

Masalahnya sekarang adalah bagaimana agar pengajaran bahasa Inggris mampu membuat mahasiswa berkomunikasi secara lisan dengan baik dan benar seperti harapan yang telah disusun dalam kurikulum atau silabus. Sebab, kalau pengajaran bahasa hanya menekankan pada bentuk-bentuk formal kebahasaan, jelas akan ada sesuatu yang kurang untuk mencapai tujuan tersebut, yaitu tidak tersentuhnya aspek sosio-kultural. Maka dari itu, pengajaran bahasa Inggris untuk keperluan industri pariwisata di Indonesia tidak boleh mengesampingkan aspek sosio-kulturalnya agar kesenjangan budaya yang bisa menimbulkan salah tafsir atau salah pengertian pada saat berinteraksi bisa dikurangi.

\section{MENYIKAPI PENGAJARAN "ENGLISH FOR GUIDING" BERBASIS PENDEKATAN SOSIOKULTURAL}

Para penyusun silabus pengajaran bahasa Inggris untuk keperluan industri pariwisata (diantaranya English for Guiding) cenderung menginginkan peserta didiknya atau lulusannya (out put) mampu berkomunikasi secara lisan maupun tulisan dengan baik dan benar. Untuk mencapai sasaran itu, tugas utama para guru atau dosen bukan saja memberikan bentuk-bentuk formal kebahasaan tetapi juga memberikan pengetahuan tentang aspek-aspek sosiokultural. Ini sejalan dengan apa yang dikatakan oleh Stern (1983) bahwa pemahaman budaya dan horizon perbandingan antarbudaya adalah salah satu komponen yang sangat perlu dalam pengajaran bahasa, terlebih lagi pengajaran bahasa asing.

Dikatakan oleh Chamberlain (2005) bahwa budaya merujuk pada nilainilai, norma, dan tradisi yang mempengaruhi individu dari kelompok masyarakat 
untuk bertindak, berpikir, bereaksi, bertingkah laku dan membuat keputusan tentang dunia mereka.

Sudah menjadi pemandangan yang lumrah seorang pelajar bahasa asing yang tidak memiliki cukup pengetahuan dan latar belakang budaya masyarakat yang bahasanya sedang dipelajari ada kecenderungan memakai norma sosial atau budayanya sendiri sehingga tidak jarang terjadi ketersinggungan atau pesan yang ingin disampaikan tidak mengenai sasaran seperti yang diinginkan. Kita ambil saja contoh kesalahan penerapan budaya yang sering kita lihat di Bali dan penulis yakin juga terjadi di daerah-daerah lain di Indonesia. Misalnya, bagaimana seseorang menyapa wisatawan asing dengan "Hello, Mister. Where are you going?” ( Hai, Tuan. Kemana Anda pergi?). Semestinya dia menyapa dengan "Good morning” atau "Hello" saja (selamat pagi atau hai).

Dengan sapaan "selamat pagi" atau "hai" sudah cukup dianggap sopan dan wajar. Bagi orang barat, pemakaian sapaan "Hai, tuan, Anda mau kemana" terdapat setidaknya tiga kesalahan dari tinjauan sosiokultural (Mashadi Said, Jane Fowles,1991: 1). Yang pertama, penggunaan intonasi atau suara yang biasanya agak berteriak keras, padahal seharusnya hanya menggunakan intonasi yang datar saja. Yang kedua, penggunaan kata sapaan "mister". Penggunaan kata "mister" tidak pada tempatnya. Dan yang ketiga, menanyakan "Kemana anda pergi" (Where are you going) dianggap bersifat terlalu pribadi yang tidak perlu ditanyakan atau tidak perlu diketahui oleh orang lain yang bukan teman dekatnya dan tidak punya urusan dengannya.

Ini sejalan dengan apa yang dikemukakan oleh Hymes (1972) bahwa kompetensi komunikatif menuntut pengetahuan tidak hanya kode-kode bahasa dan bentuk-bentuk formal bahasa, namun juga sangat perlu memperhatikan aspek pragmatiknya: “apa" yang ingin disampaikan kepada "siapa” dan bagaimana cara untuk menyampaikannya dengan tepat dalam situasi tertentu agar apa yang ingin disampaikan mencapai sasaran yang tepat.

Implikasi dari apa yang dikatakan oleh Hymes menyaran pada pentingnya pemahaman akan aspek-aspek sosiokultural yang mesti menjadi perhatian si pembicara dalam berinteraksi. Pengetahuan sosiokultural ini memungkinkan si pembicara menggunakan dan menafsirkan bentuk-bentuk atau ungkapan- 
ungkapan bahasa yang semestinya digunakan. Ini juga menyaran pada siapa yang patut dan tidak patut untuk berbicara pada latar (setting) tertentu, kapan harus berbicara dan kapan harus diam, bagaimana harus berbicara pada orang yang mempunyai status sosial atau peran-peran tertentu dalam masyarakat.

Lin (2010) mengatakan bahwa kompetensi komunikatif dibagi dalam dua kategori yaitu kompetensi organisasi yang menyangkut gramatikal dan discourse atau wacana (tekstual) serta kompetensi pragmatik yang menyangkut kompetensi sosiolinguistik dan kompetensi illocutionary atau strategi pemakai bahasa. Kompetensi strategi dikaitkan dengan kemampuan si pemakai bahasa dalam memilih dan menggunakan strategi komunikasi.

Hal ini juga disitir oleh Richard (1985) yang mengatakan bahwa kompetensi komunikatif adalah kemampuan yang tidak saja hanya mengacu pada penggunaan atau penerapan bentuk-bentuk gramatikal bahasa yang memungkinkan seseorang untuk menyusun kalimat-kalimat yang baik dan benar, tetapi juga sangat perlu mengetahui kapan dan di mana kalimat-kalimat tersebut digunakan dan untuk siapa kalimat-kalimat itu digunakan. Seperti dikatakan oleh Littlewood bahwa salah satu ciri khas utama pengajaran bahasa komunikatif adalah pemberian perhatian sistematis terhadap aspek-aspek fungsional dan struktural bahasa (Littlewood dalam Chaedar Alwasilah, A dkk, 1996)

Dengan demikian, penggunaan bahasa yang sesuai dan tepat untuk mencapai tujuan tertentu adalah hal yang sangat krusial untuk direnungkan, dipertimbangkan oleh pembicara dalam berinteraksi. Bilamana penggunaan ungkapan-ungkapan kebahasaan tidak sesuai, di sinilah kemungkinan besar akan terjadi ketersinggungan-ketersinggungan, atau mungkin juga apa yang disampaikan terkesan lucu, aneh, kasar, walaupun pembicara telah menggunakan bahasa yang secara idiomatik baik. Hal inilah yang sangat perlu diberikan kepada mahasiswa agar nantinya mereka mempunyai pemahaman yang benar akan perbedaan budaya dengan wisatawan yang nantinya mereka tangani. 


\section{SEKILAS PERBEDAAN BUDAYA ANTARA MASYARAKAT INGGRIS (BUDAYA BARAT) DAN INDONESIA}

Bila tujuan utama pengajaran bahasa Inggris untuk industri pariwisata (English for guiding) adalah mempersiapkan siswa/mahasiswa agar mampu berkomunikasi secara lisan, guru/dosen bahasa Inggris atau bahasa asing pariwisata dituntut untuk memiliki pengetahuan tentang perbedaan-berbedaan budaya kedua masyarakat yang bahasanya dipelajari, karena antara budaya barat (misalnya : Inggris, America dan sebagainya ) dan Indonesia terdapat perbedaan yang perlu untuk mendapat perhatian khusus. Beberapa contoh perbedaan budaya kedua masyarakat, adalah pada contoh di bawah ini.

Pada masyarakat etnis Bali dan juga beberapa etnis lain di Indonesia, ketika menunjuk sesuatu atau memberikan sesuatu kepada seseorang apalagi kepada orang yang lebih tua dengan menggunakan tangan kiri dianggap sangat tidak sopan. Sedangkan bagi masyarakat Inggris, Amerika dan negara-negara barat lainnya menunjuk atau memberikan sesuatu dengan tangan kiri adalah biasa biasa saja dan sudah lumrah, tidak menimbulkan ketersinggungan sama sekali pada masyarakat mereka.

Contoh yang lain, bagi orang Bali, memegang kepala orang lain tanpa permisi dianggap suatu perbuatan yang sangat tidak sopan. Pemandangan seperti ini sering penulis lihat pada waktu masih menjadi pemandu wisata di Denpasar Bali, di mana seorang wisatawan (tourist) memegang atau malah menggosokgosok kepala pemandu wisatanya. Bagi orang Inggris, Australia, Amerika dan lain-lain, memegang kepala orang lain, tentunya yang mereka kenal, merupakan wujud ekspresi keakraban. Bagi pemandu wisata yang tidak memahami budaya mereka sangatlah mungkin menimbulkan ketersinggungan yang luar biasa, lebihlebih lagi yang dipegang adalah kepala orang yang mempunyai status sosial lebih tinggi, seperti kaum brahmana atau kaum yang mempunyai darah biru.

Contoh yang ketiga, bagi orang Indonesia bergotong royong atau saling membantu sangat penting dan sudah merupakan budaya yang patut untuk dikembangkan. Maka dari itu, pada budaya Indonesia, menawarkan bantuan kepada orang lain bila situasi menghendaki demikian adalah sangat lumrah dan malah bagus sekali dan sangat dianjurkan dalam etika pergaulan di masyarakat 
kita di Indonesia. Sebaliknya, bagi orang barat, sudah terbiasa dengan kehidupan yang individualistis, berpikir dan bertindak sendiri atau dengan kelompoknya saja. Bagi mereka yang sudah terbiasa hidup individualistis, penawaran atau uluran akan bantuan dari orang lain sering dianggap sebagai gangguan terhadap kehidupan pribadinya (privacy), dan bagi mereka dianggap kurang tepat.

Ada cerita dari seorang mahasiswa Indonesia yang belajar di Amerika, secara kebetulan bertemu dengan seseorang yang invalid (cacat) sedang duduk di kursi roda di jalan raya yang ingin menyeberang jalan. Naluri budaya Indonesia seketika muncul dan mencoba untuk mengulurkan bantuan dengan mengatakan :" Bisa saya bantu, Pak" (Can I help you, sir). Alangkah terkejutnya dia mendengar reaksi orang yang sedang di kursi roda yang hendak ditolongnya dengan respon sangat negatif dan kemudian terus pergi dengan muka sinis. Di sini jelas terjadi kesenjangan pemahaman budaya antara dua insan yang berbeda latar sosial budaya: budaya Amerika dan Indonesia.

\section{MENGUSAHAKAN KEWAJARAN (APPROPRIACY)}

Kalau kompetensi komunikatif sudah menjadi komitmen dan telah diputuskan sebagai tujuan dari kurikulum yang menginginkan siswa/mahasiswa agar mampu berkomunikasi dengan wajar dan sukses, maka merupakan suatu keharusan bagi guru/dosen untuk memasukkan aspek-aspek sosiokultural dalam proses belajar mengajarnya (PBM) sebagai sesuatu yang wajib yang sering disebut dengan istilah "kesesuaian dalam materi" (appropriacy in the materials) (Mashadi, Jane power, 1991).

Pengajaran tentang aspek-aspek sosiokultural sebaiknya diintegrasikan dengan pengajaran grammar (tata bahasa), kosa kata dan skill atau keterampilan lainnya. Kalau ini tidak dilakukan, para siswa/ mahasiswa tidak akan sampai pada sasaran utamanya, yaitu penguasaan bahasa yang berhasil dan tepat guna. Melalui penerapan bentuk-bentuk bahasa dalam pengajaran, guru/dosen dituntut untuk berusaha menyadarkan siswa/ mahasiswa akan pentingnya isu/wacana yang sedang dipelajari, di samping tentunya juga tentang sikap atau kebiasaankebiasaan sosial masyarakat yang bersangkutan yang bahasanya sedang dipelajari. Hal ini dapat membantu mereka untuk memahami perbedaan-perbedaan budaya 
dan pada akhirnya diharapkan dapat menghilangkan atau setidaknya meminimalkan antipati terhadap budaya-budaya lain yang memang berbeda.

Masalahnya sekarang menyusun materi pengajaran dengan berbasiskan aspek-aspek budaya seperti tersebut di atas tidaklah gampang, terutama bagi mereka yang tidak pernah bersentuhan langsung dengan budaya masyarakat yang bahasanya sedang dipelajari. Lebih ironis lagi, materi-materi yang siap saji sangat sulit untuk didapatkan sampai sekarang. Materi yang bagaimana sebaiknya dipersiapkan bagi mereka yang akan ke luar negeri. Namun yang paling kita butuhkan sekarang adalah materi-materi yang urgen dibutuhkan oleh siswa/mahasiswa dalam mengantisipasi dan menangani kedatangan wisatawan asing yang berkunjung ke Indonesia.

Realitas menunjukkan bahwa kebanyakan orang-orang yang bergelut dan terlibat langsung di sektor pariwisata masih banyak yang belum mengenyam pendidikan tinggi. Dengan demikian, sangatlah perlu memilih pendekatan yang praktis, pragmatis yang mengarah pada kemampuan dan keperluan langsung para siswa/mahasiswa. Dalam hal ini menurut penulis, dalam mengimplementasikan materi pengajaran, penggunaan lebih banyak permainan atau bermain peran (role play), simulasi, bermain drama, dan juga aktifitas komunikatif berpasangpasangan sangatlah efektif untuk diterapkan. Pengajaran sebaiknya bersifat situasional fungsional. Akan lebih baik lagi jika guru/dosen bisa merancang materi-materi yang bermuatan sosiokultural yang dirancang dengan baik melalui cuplikan-cuplikan video. Aktifitas ini sangatlah mendukung kegiatan proses belajar-mengajar bahasa asing berbasiskan pendekatan sosiokultural.

Sebagai contoh, misalnya, sebuah cuplikan film yang memperlihatkan adegan di mana wisatawan disapa oleh orang lokal di suatu tempat di Indonesia dengan mengatakan: "Hello, Mister. Where are you going". Diperlihatkan juga bagaimana reaksi wisatawan dengan sapaan seperti itu. Ini salah satu contoh materi sederhana yang sangat efektif disuguhkan kepada siswa/mahasiswa. Contoh-contoh seperti itu bisa diproduksi sendiri oleh para dosen, tentunya dengan bantuan dana dari lembaga akan sangat bagus. 


\section{PERAN DOSEN PENGAJAR BAHASA INGGRIS KHUSUS (ESP)}

Di sini peran dosen yang memiliki horizon pengetahuan yang komprehensif akan budaya-budaya barat sangat diperlukan, lebih menguntungkan lagi kalau yang pernah tinggal dan bersentuhan langsung dengan budaya barat. Kondisi itu sangatlah menguntungkan dan bisa membantu mahasiswa karena mereka dapat belajar dari pengalaman guru/dosen karena mahasiswa pada umumnya jarang bersentuhan secara langsung dengan bahasa dan budaya barat. Persepsi mereka yang salah akan budaya barat bisa jadi menimbulkan kejengkelan, ketersinggungan terhadap orang barat. Kesalahan persepsi ini mungkin disebabkan oleh kurangnya kesempatan kontak langsung mahasiswa terhadap bahasa dan budaya barat atau mungkin informasi itu diperoleh dari sumber-sumber kedua yang sering kali menyesatkan. Idealnya seperti dikatakan oleh Kutchinson dan Waters (1987:157) bahwa dosen ESP harus berusaha untuk melakukan analisis keperluan mahasiswa, merancang silabus, kemudian membuat materi pengajaran sesuai dengan keperluan, serta tentunya mengadakan evaluasi terhadap apa yang telah dibuatnya.

Lebih lanjut dikatakan oleh Littlewood (1985:1), bahwa metode dan teknik pengajaran dosen sering tidak berhasil mencapai pengajaran yang efektif, meskipun secara teori metode dan teknik tersebut tampaknya sudah sangat baik. Untuk mengatasi hal tersebut tidak boleh tidak dosen harus memahami dan mempelajari secara mendalam akan karakteristik mahasiswanya.

Konsekuensinya, dosen dalam menyusun silabus atau materi pengajarannya dituntut untuk jeli memahami, mencermati kebutuhan mahasiswa. Karena silabus yang disusun berkaitan dengan bahasa Inggris (English for Guiding) sudah tentu juga harus mencermati kesenjangan budaya antara budaya barat dan budaya lokal yang dimiliki mahasiswa di samping bentuk-bentuk bahasa yang menjadi sasaran utamanya. Ini bisa dilakukan kepada mahasiswa dengan memberikan informasi yang akurat yang dapat menantang mereka agar melakukan reorientasi berpikir tentang asumsi-asumsi yang mungkin terlanjur salah. 


\section{SIMPULAN}

Industri pariwisata di Indonesia tidak henti-hentinya dipromosikan melalui berbagai media, baik cetak maupun elektronik, karena industri yang satu ini mampu menyerap tenaga kerja yang sangat banyak.

Dalam kenyataannya, salah pengertian antara para pelaku pariwisata dengan wisatawan tidak bisa dihindari sebagai dampak dari persinggungan multi budaya dalam masyarakat yang multikultural. Menyadari hal ini, tidak bisa ditawar lagi, kita semua sebagai komponen anak bangsa harus mengambil tindakan yang konkret dalam mengantisipasi isu perbedaan budaya tersebut. Salah satu wujud konkret tersebut adalah melalui pendidikan baik pendidikan formal, nonformal maupun informal.

Pengajaran bahasa Inggris Pariwisata (English for Guiding) yang berbasiskan pendekatan sosiokultural adalah salah satu jawaban dari isu tersebut sehingga kesalahpahaman karena masalah kesenjangan budaya (cultural gap), syak wasangka dan antipati karena perbedaan budaya bisa dihilangkan atau setidaknya diminimalkan, sehingga pembangunan sektor pariwisata yang menjadi tumpuan harapan sebagian masyarakat Indonesia bisa berjalan seperti yang diharapkan. Semoga!

\section{DAFTAR PUSTAKA}

Azies, Furqanul, Chaedar Alwasilah, A. 1996. Pengajaran Bahasa Komunikatif, Teori dan Praktek. Bandung : PT. Remaja Rosda Karya.

English Teaching Forum, Volume XXII, Number 2, 1979.

Hutchison, Tom and Alan Water. 1987. English for Specific Purposes. Cambridge : Cambridge University Press.

Hymes. D.H. 1972. "On Communicative Competence, In J.B. Pride and J. Holmes (Eds). Sociolinguistics". Harmondsworth : Pinguin Books.

Littlewood,W., 1985. Foreign and Second Language Learning. Cambridge: Cambridge University Press.

Richard, Jack C, 1985. The Context of Language Teaching. Cambridge:Cambridge University Press.

Said, Mashadi, Jane Fowles.1991."Toward A Cultural-Based Approach to Teaching EFT in Indonesia", Makalah Seminar Teflin.

Stern, H.H. 1983. Fundamental Concept of Language Teaching. London: Oxford University Press. 


\section{DAFTAR KEPUSTAKAAN}

Alessandro Duranti. 1997. Linguistic Anthropology. United Kingdom : Cambridge University Press. 
Blundel, John, Jonathan Higgins and Nigel Middlemiss. 1982. Function in English. New York : Oxford University Press.

Brumfit, C.J. and K.Johnson. 1983. The Communicative Approach to Language Teaching. New York : Oxford University Press.

Dardjowidjoyo, Soejono. 1989. Sentence Patterns on Indonesian. University of Hawaii Press, Honolulu.

Dubin, Fraida and Olahtain Elito. 1986. Course Design : Developing Programme and Materials for Languge Learning. Cambridge: Cambride University Press.

Hutchison, Tom and Alan Water. 1987. English for Specific Purposes. Cambridge : Cambridge University Press.

Hymes. D.H. 1972. “On Communicative Competence, In J.B. Pride and J. Holmes (Eds). Sociolinguistics”. Harmondsworth : Pinguin Books.

Lin, G.H.2007. A case Study about Seven Taiwanese English as a Foreign Language Freshmen Majors' Perception about Learning Five Communication Strategies, Bacon Ratan Florida : Dissertation.co.Publishing ISBN Number . 158112374-4

Lin, G.H.2010. Book review of Strategies in Interlanguage Communication, C.Faerach and G. Kasper. (eds) new York : Longman.

Mashadi Said, Jane Fowles.1991.'Toward A Cultural-Based Approach to Teaching EFT in Indonesia", Makalah Seminar Teflin di Mataram.

Stern, H.H. 1983. Fundamental Concept of Language Teaching. London: Oxford University Press. 